\title{
Differential Expression of Synaptophysin and Synaptoporin During Pre- and Postnatal Development of the Rat Hippocampal Network
}

\author{
D. Grabs ${ }^{1}$, M. Bergmann', Th. Schuster ${ }^{1,4}$, P. A. Fox ${ }^{1}$, M. Brich ${ }^{2}$ and M. Gratzl ${ }^{3}$ \\ ${ }^{1}$ Institut für Anatomie (Charité), Humboldt-Universität Berlin, D-10098 Berlin, Germany \\ ${ }^{2}$ Naturwissenschaftliches und Medizinisches Institut an der Universität Tübingen, D-72762 Reutlingen, Germany \\ ${ }^{3}$ Abteilung Anatomie und Zellbiologie, Universität Ulm, D-89069 Ulm, Germany \\ ${ }^{4}$ Present address: Abteilung Neurobiologie, ETH Zürich, $\mathrm{CH}-8093$ Zürich, Switzerland
}

Key words: synaptic vesicle membrane protein, dentate gyrus, cornu ammonis

\begin{abstract}
The closely related synaptic vesicle membrane proteins synaptophysin and synaptoporin are abundant in the hippocampal formation of the adult rat. But the prenatal hippocampal formation contains only synaptophysin, which is first detected at embryonic day 17 (E17) in perikarya and axons of the pyramidal neurons. At E21 synaptophysin immunoreactivity extends into the apical dendrites of these cells and in newly formed terminals contacting these dendrites. The transient presence of synaptophysin in axons and dendrites suggests a functional involvement of synaptophysin in fibre outgrowth of developing pyramidal neurons. Synaptoporin expression parallels the formation of dentate granule cell synaptic contacts with pyramidal neurons: the amount of hippocampal synaptoporin, determined in immunoblots and by synaptoporin immunostaining of developing mossy fibre terminals, increases during the first postnatal week. Moreover, in the adult, synaptoporin is found exclusively in the mossy fibre terminals present in the hilar region of the dentate gyrus and the regio inferior of the cornu ammonis. In contrast, synaptophysin is present in all synaptic fields of the hippocampal formation, including the mossy fibre terminals, where it colocalizes with synaptoporin in the same boutons. Our data indicate that granule neuron terminals differ from all other terminals of the hippocampal formation by the presence of both synaptoporin and synaptophysin. This difference, observed in the earliest synaptic contacts in the postnatal hippocampus and persisting into adult life, suggests distinct functions of synaptoporin in these nerve terminals.
\end{abstract}

\section{Introduction}

The rat hippocampal formation provides an ideal model to analyse the composition of the synaptic vesicle membranes because the hippocampal cytoarchitecture, synaptic connections and neurotransmitters are well understood. For example, the axons of dentate granule neurons (mossy fibres) traverse the hilus of the dentate gyrus, form axonal collaterals and terminate as en passant synapses on hilar interneurons (for review see Amaral, 1978). Specifically, they terminate as large boutons on dendrites apical and basal to the cell bodies of cornu ammonis 4 (CA4) pyramidal neurons as well as the proximal part of the apical dendrites of CA3 pyramidal neurons (Blackstad and Kjaerheim, 1961). In addition, dentate granule neurons form smaller synapses with non-pyramidal interneurons in the CA3 region (Frotscher, 1985). Glutamate is the principal excitatory transmitter in the hippocampal formation involved in signalling between granule and pyramidal neurons (Crawford and Connor, 1973). Glutamate excites granule neurons via perforant path axons and conveys signals between the pyramidal neurons of CA3 and CAl via Schaffer collaterals.

Synaptic vesicles contain characteristic proteins, including synaptophysin and synaptoporin (Jahn and De Camilli, 1991; Jahn and Südhof, 1994). Synaptophysin and synaptoporin are members of the putative channel protein family present in the membranes of synaptic vesicles (for review see Betz, 1990). These proteins are characterized by four transmembrane domains and $\mathrm{N}$ - and $\mathrm{C}$-terminals exposed to the cytoplasmic side (Johnston et al., 1989b; Knaus et al., 1990). Until recently, the composition of synaptic vesicle membranes was believed to be similar. Evidence now available reveals that synaptophysin and synaptoporin are differentially expressed in subpopulations of rat central nervous system neurons (Marquèze-Pouey et al., 1991; Bergmann et al., 1993; Ovtscharoff et al., 1993).

The hippocampus contains large amounts of synaptophysin and synaptoporin. In the present study we focused on the differential 
expression of synaptophysin and synaptoporin in adult and developing hippocampal neurons.

\section{Materials and methods}

Adult and pregnant rats (Sprague-Dawley) were purchased from Charles River (Sulzfeld, Germany). The animals were anaesthetized with $4 \%$ chloral hydrate $(1 \mathrm{ml} / 100 \mathrm{~g}$ body weight). Embryonic brains were obtained from pregnant rats on days 17 and 21 (E17, E21; day of insemination $=$ day 0 ). Brains were removed from newborn (postnatal day $0, \mathrm{P} 0$ ), young postnatal (P3, P5 and P8) and adult rats and processed as follows.

Tissues from different rat brain areas were frozen in liquid nitrogen. The samples were homogenized and proteins $(10 \mu \mathrm{g}$ per lane for the detection of synaptophysin and $20 \mu \mathrm{g}$ for synaptoporin) were separated by sodium dodecyl sulphate-polyacrylamide gel electrophoresis (Laemmli, 1970) and transferred to nitrocellulose (Towbin et al., 1979) as described previously in detail (Lahr et al., 1990; Bergmann et al., 1991). For the detection of antigen in blots, polyclonal rabbit antisera directed against rat synaptophysin (kindly provided by $R$. Jahn, New Haven, CT) or synaptoporin (kindly provided by H. Betz, Frankfurt/Main, Germany) were used. The antisera were diluted 1:1000 (anti-synaptophysin) or 1:200 (anti-synaptoporin) in PBS containing $0.5 \%$ bovine serum albumin and $0.05 \%$ sodium azide. Antigen/antibody complexes were visualized using the avidin-biotinperoxidase complex (ABC) technique (Hsu et al., 1981). For quantification the optical density of the immunoreactive bands was measured in the linear range of detection (Schilling and Gratzl, 1988).

For immunohistochemistry, paraffin sections $(6 \mu \mathrm{m})$ of Bouin-fixed brains were mounted on gelatine-coated slides. In addition, vibratome sections $(20 \mu \mathrm{m})$ fixed with $4 \%$ paraformaldehyde in $0.1 \mathrm{M}$ phosphate buffer ( $\mathrm{pH} \mathrm{7.4)}$ were used for the investigation of the developing hippocampus as well as for double immunostaining. Sections were incubated with the same antibodies as those used for immunoblotting. For double immunofluorescence studies, monoclonal mouse synaptophysin (1:50; Progen, Heidelberg, Germany) and polyclonal synaptoporin antiserum (see above) were used. Details of the subsequently applied $\mathrm{ABC}$ technique have been described previously (Bergmann et al., 1993; Ovtscharoff et al., 1993). Fluorescein-labelled rat IgG and Texas red-labelled avidin, which binds to biotinylated mouse IgG [Camon, Wiesbaden, Germany] were used for immunofluorescence. Double immunofluorescence was examined with a confocal laser scanning microscope (Zeiss LSM 410) and a high-resolution objective (Zeiss Plan-Apochromat $63 \times / 1.4$ oil) in two separate detection channels (excitation $488 \mathrm{~nm} / \mathrm{emission} 515-545 \mathrm{~nm}$; ex 543/em $>590 \mathrm{~nm}$ ). Controls incubated with $2 \%$ ( vol/vol) normal goat and/or normal horse serum in phosphate-buffered saline or with normal rabbit serum (1:1000) instead of the first antibody were negative.

For ultrastructural studies rats were perfused through the ascending aorta with a fixative containing $2 \%$ paraformaldehyde, $0.5 \%$ glutaraldehyde, $1 \%$ acrolein, $2.5 \%$ dimethyl sulphoxide ( $\mathrm{vol} / \mathrm{vol})$ and $9 \mathrm{mM}$ $\mathrm{CaCl}_{2}$ in $0.1 \mathrm{M}$ cacodylate buffer ( $\mathrm{pH} 7.2$ ). Brains were removed, postfixed in the same fixative for $4 \mathrm{~h}$ and placed in phosphatebuffered saline overnight. Sections $(20 \mu \mathrm{m})$ were cut on a vibratome and processed for pre-embedding staining employing the $\mathrm{ABC}$ technique (Bergmann et al., 1993; Ovtscharoff et al., 1993). Briefly, sections were incubated with the first antibodies for $48 \mathrm{~h}$, and second antibodies as well as the detection system were applied for $2 \mathrm{~h}$. Specimens were postfixed in $1 \% \mathrm{OsO}_{4}$ for $45 \mathrm{~min}$, dehydrated and embedded in Epon. Ultrathin sections were stained with $4 \%$ uranyl acetate and $0.2 \%$ lead citrate.

\section{Results \\ Distribution of synaptophysin and synaptoporin in the rat central nervous system}

Western blots revealed a strong synaptophysin-immunoreactive band of $38 \mathrm{kDa}$ in extracts of the hippocampal formation and the neocortex. Fainter bands were detected in the olfactory bulb, the cerebellum and the spinal cord (Fig. 1A).

Synaptoporin, migrating slightly faster $(37 \mathrm{kDa})$, was highest in the hippocampal formation and the neocortex. A faint band was detected in the olfactory bulb. In contrast, in the cerebellum and the spinal cord no immunoreactive bands for synaptoporin were seen (Fig. 1B).

In the hippocampal formation synaptoporin increased during the first postnatal week (Fig. 1C). Quantification of synaptoporin in immunoblots carried out with samples of the developing hippocampal formation showed $27.7 \%$ (SD $6.6 \% ; n=5$ ) of the adult level on P3 and $44.5 \%$ (SD $4.2 \% ; n=5$ ) on P5 (Fig. 1D).

\section{Expression of synaptophysin and synaptoporin in the hippocampus during development}

Synaptophysin immunoreactivity was first detected on E17 in perikarya of pyramidal cells, in fibres between their cell bodies (Fig. 2A) and in the fimbria hippocampi (Fig. 2B). At E21 synaptophysin immunoreactivity was found in the apical dendrites of pyramidal cells (Fig. 2C). Moreover, punctate staining was found in all terminal fields of the hippocampal formation (Fig. 2D), including the developing stratum lucidum. In summary, observations revealed that during prenatal development synaptophysin appears first in pyramidal cell bodies and their axons and subsequently in apical dendrites of pyramidal cells and the newly formed terminals of the hippocampal formation.

All hippocampal terminal fields showed punctate synaptophysin immunoreactivity in postnatal and adult rats (see also Fig. 5A). The developing dentate gyrus granule cells of postnatal rats (up to day 8) exhibited perikaryal staining (not shown), while the axons and dendrites of postnatal pyramidal cells were immunonegative.

Immunostaining first detected synaptoporin at P3 in the terminal field of the hippocampal granule neurons in the stratum lucidum of CA3 (Fig. 3A). Thereafter, synaptoporin immunoreactivity increased between P5 (not shown) and P8 (Fig. 3B). In the hilar region of the dentate gyrus, as well as in the suprapyramidal and infrapyramidal layer of CA4, immunoreactivity for synaptoporin was also first observed at P3 and was more intense at P8 (not shown). No immunostaining for synaptoporin was detected in the hippocampal formation in the prenatal period and at P0. Taken together, synaptoporin immunoreactivity was only observed postnatally in terminal fields of developing granule neurons.

\section{Expression of synaptophysin and synaptoporin in the adult hippocampal formation}

Immunostaining for synaptoporin in the adult was restricted to the hilar region of the dentate gyrus, the supra- and infrapyramidal layers in CA4 and the stratum lucidum of CA3 (Fig. 4A). At the boundary between $\mathrm{CA} 3$ and $\mathrm{CA} 2 / 1$ an abrupt decrement in synaptoporin immunoreactivity was evident (Fig. 4A). The localization of synaptoporin immunoreactivity is consistent with the synaptic field of the mossy fibre system.

Ultrastructural observations revealed numerous synaptoporinimmunostained synaptic vesicles in the giant mossy fibre boutons 

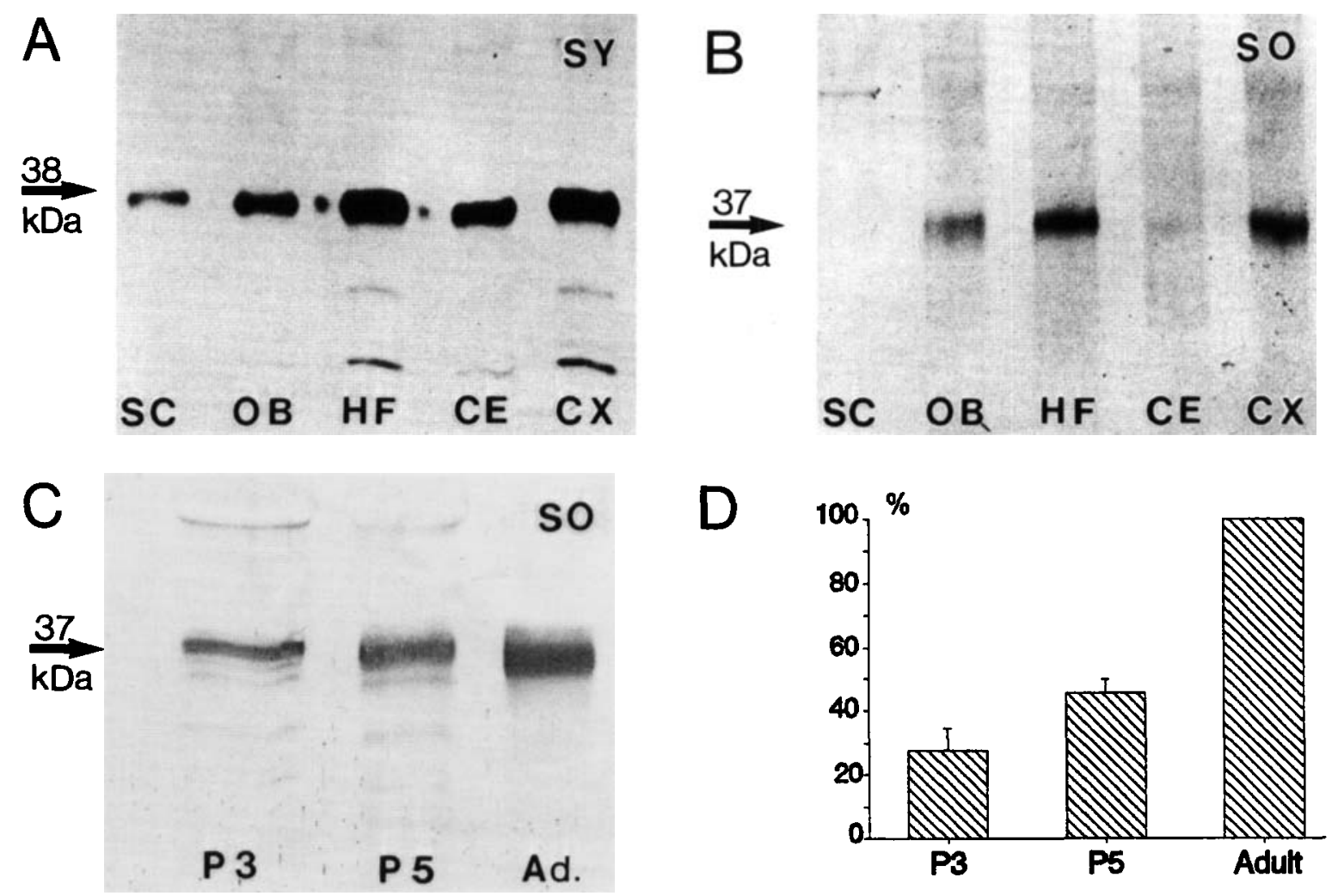

FIG. I. Distribution of synaptophysin and synaptoporin in different parts of the central nervous system. (A) Immunoblots revealed large amounts of synaptophysin (SY) in the hippocampal formation (HF) and the neocortex (CX) and less in the spinal cord (SC), the olfactory bulb (OB) and the cerebellum (CE). (B) Synaptoporin (SO) was most abundant in the hippocampal formation and the neocortex, but less in the olfactory bulb. No immunoreactive bands were observed in samples of the spinal cord and the cerebellum. (C) The amounts of synaptoporin increased during hippocampal development between postnatal day 3 (P3), P5 and adult. (D) Quantification of the intensities of the bands revealed $27.7 \pm 6.6 \%$ (SD, $n=5$ ) and $44.5 \pm 4.2 \%(n=5$ ) of the adult level at P3 and P5 respectively. Arrows point to the immunoreactive synaptoporin and synaptophysin bands and give their molecular masses determined in sodium dodecylsulphate-polyacrylamide gel electrophoresis. For details and evaluation of the linearity see Materials and methods.

(Fig. 4B). Some terminals with unlabelled synaptic vesicles were found in the vicinity of heavily stained terminals (Fig. 4B). Light and electron microscopic observations revealed that mossy fibre terminals also contain synaptophysin; for example, synaptophysinimmunostained mossy fibre boutons were found in CA3 (Fig. 5A). The distribution of synaptoporin in the same section was also documented with confocal laser microscopy (Fig. 5B). Most mossy fibre terminals contained both synaptophysin and synaptoporin (Fig. $5 \mathrm{C}$ ), whereas synaptophysin was present in smaller terminals in the stratum radiatum and other layers of the same region (Fig. 5A, C).

\section{Discussion}

Synaptic vesicle membrane proteins participate in the storage of neurotransmitters, in the docking, fusion and recycling of synaptic vesicles. The functions of carriers and the electrochemical proton gradient during accumulation of neurotransmitters in synaptic vesicles are evident. Recent observations on the effect of clostridial neurotoxins and complexes formed between synaptic vesicle membrane proteins and other components of the nerve terminal suggest that synaptobrevin and synaptotagmin are essential elements of the exocytosis machinery of synaptic vesicles (O'Connor et al., 1993; Söllner et al., 1993). However, the precise roles of these two proteins in regulated neurotransmission remain to be defined. The most abundant synaptic vesicle protein, synaptophysin, and its congener synaptoporin have been proposed to participate as oligomers in the formation of the pore-initiating membrane fusion (Thomas et al., 1988; Knaus et al., 1990).

Studies on the developmental expression of synaptophysin and synaptoporin in the central nervous system revealed that these proteins are present not only in mature terminals but also in outgrowing axons (Bergmann et al., 1991, 1993; Scarfone et al., 1991; Ovtscharoff et al., 1993; this study) and, unexpectedly, in the cytoplasmic bridge connecting retinal photoreceptor cell bodies with the rod component (Schmied and Holtzman, 1989), in dendrites of the continuously regenerating olfactory receptor neurons (Bergmann et al., 1993) and, transiently, in dendrites of developing hippocampal pyramidal neurons (this study). While synaptic vesicles in outgrowing axons could serve as a reservoir for subsequent synaptogenesis, synaptic vesicle membrane antigens in developing dendrites are unlikely to contribute to synaptic organelles. Thus it is possible that synaptophysin exists in dendritic subcellular structures different from synaptic vesicles. In a variety of cells, evidence has been provided for this notion: for example, in PC1 2 cells synaptophysin is present in the early endosomal compartment (Linstedt and Kelly, 1991b; Régnier-Vigouroux et al., 1991; Lah and Burry, 1993); synaptophysin and synaptoporin associate with early endosomes in transfected non-neuronal cells (Johnston et al., 1989a; Cameron et al., 1991; Feany et al., 1993; Fykse et al., 1993); and synaptophysin (but not other synaptic vesicle membrane proteins) colocalizes in the perikaryal-dendritic region with the 

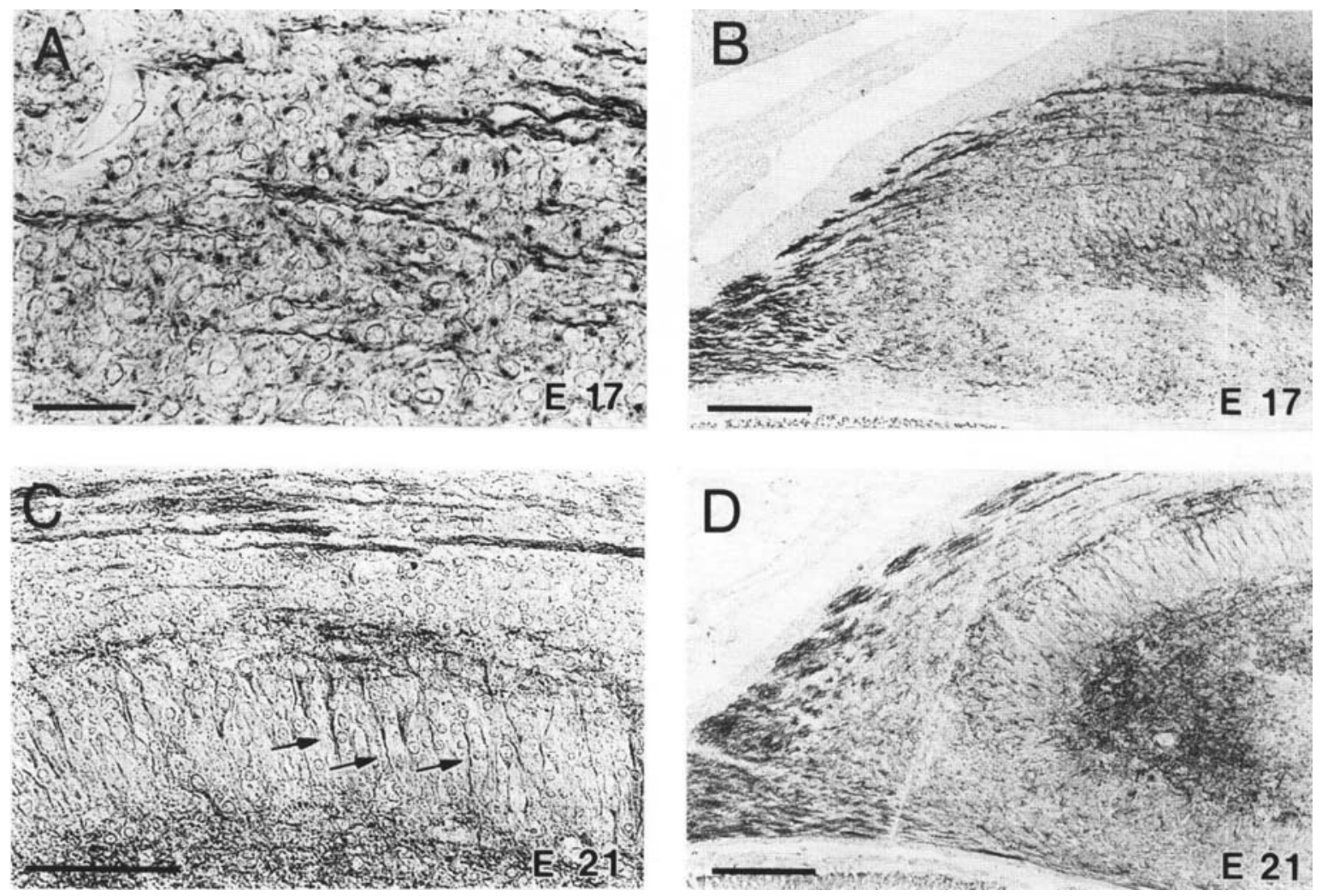

FIG. 2. Localization of synaptophysin in the developing hippocampal formation. (A) Perikarya of pyramidal cells and fibres between their cell bodies exhibited immunostaining at E17. (B) Additionally, fibres of the fimbria hippocampi were heavily stained at this stage. (C) At E21 immunoreactive dendrites (arrows) were found between the pyramidal neurons and in the developing stratum radiatum. (D) Punctate staining was detected in all synaptic fields of the hippocampal formation, including the developing stratum lucidum. Also, fibres in the fimbria hippocampi were immunopositive. Scale bars: A, $25 \mu \mathrm{m}$; B-D, 100 $\mu \mathrm{m}$.
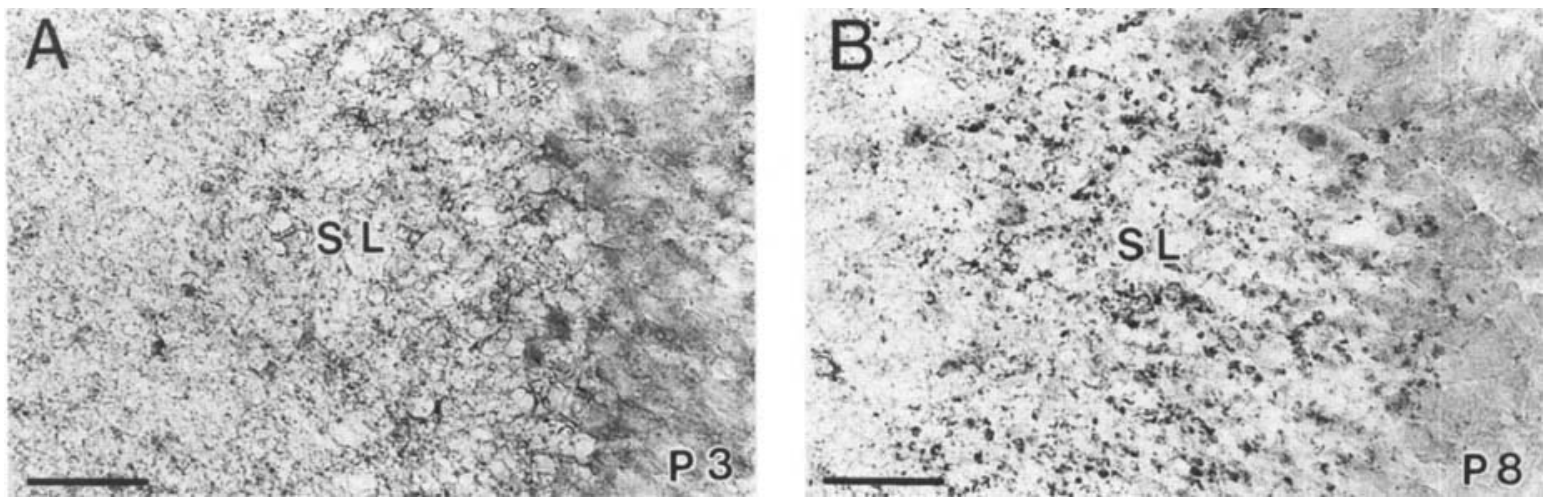

FIG. 3. Developmental expression of synaptoporin in the hippocampal formation. (A) First punctate synaptoporin immunostaining in the stratum lucidum (SL) of cornu ammonis 3 was detected at P3. (B) Immunoreactivity increased during the first postnatal week. At P8 heavily stained mossy fibre boutons were found in the stratum lucidum (SL). A and B are vibratome sections. Scale bars, $50 \mu \mathrm{m}$.

transferrin receptor, a marker for early endosomes in cultured hippocampal neurons (Mundigl et al., 1993). Thus it appears that synaptophysin participates in endosomal membrane recycling; moreover, its function during endocytosis in transfected fibroblasts is functionally linked to the cytoplasmic carboxy-terminal tail of synaptophysin (Linstedt and Kelly, 1991a). Taken together, the available data suggest that synaptophysin participates both in regulated transmitter release by mature terminals and in constitutive pathways related to the function of endosomes. In developing neurons membrane recycling is a prominent process during outgrowth of axons and dendrites and in mature synapses it is coupled to exocytosis. It is tempting to speculate that synaptophysin participates in membrane recycling during membrane biogenesis of dendrites and axons as well as in exocytosis.

The terminals of the granule neurons, the mossy fibre boutons, differ from all other terminals in the hippocampal formation, which 

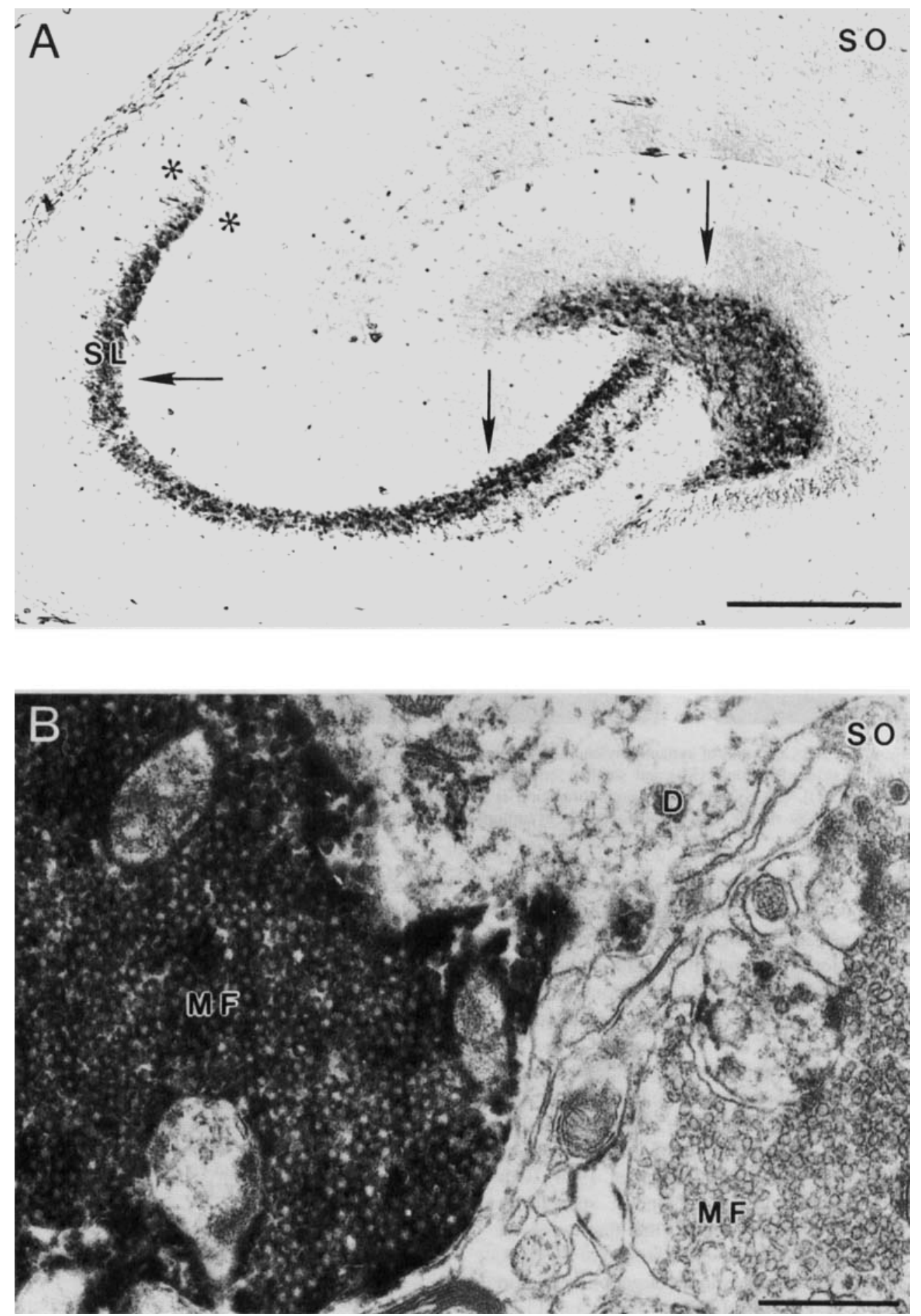

FiG. 4. Distribution and ultrastructural localization of synaptoporin in the adult hippocampal formation. (A) In the adult hippocampal formation synaptoporin (SO) is restricted to the terminal fields of the mossy fibre system (arrows). The hilus fasciae dentatae as well as the regio inferior of the cornu ammonis are heavily stained. In CA4, unstained cell bodies of pyramidal neurons separate synaptoporin-immunoreactive supra- and infra-/intrapyramidal mossy fibre boutons. Also the stratum lucidum (SL) of the CA3 region is densely labelled. The boundary to regions CA2/1 is marked with asterisks. No synaptoporin immunoreactivity was found in CA2/1 region. Scale bar, $400 \mu \mathrm{m}$. (B) Synaptoporin-immunostained and unstained mossy fibre boutons (MF) contact the same pyramidal neuron dendrite (D) in the CA4 region. Scale bar, $0.5 \mu \mathrm{m}$.

only contain synaptophysin (this study), by the presence of both synaptophysin and synaptoporin (Marquèze-Pouey et al., 1991; Fykse et al., 1993; this study). These synaptic vesicle membrane proteins differ mainly in the cytoplasmic carboxy-terminal tail (Knaus et al., 1990). Thus the putative function of these proteins during endocytosis, which is linked to this part of the molecule (Linstedt and Kelly, 

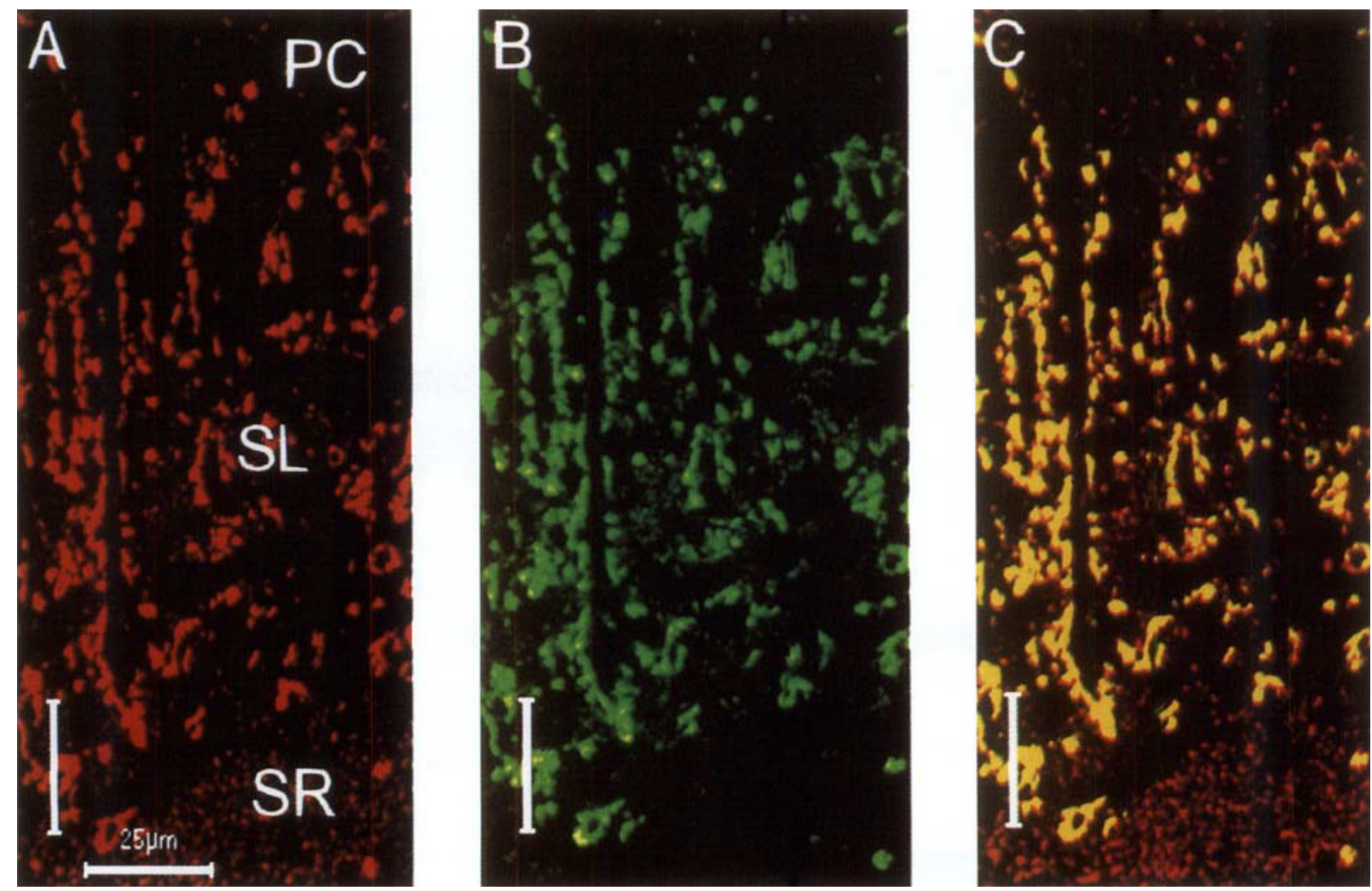

FIG. 5. Differential expression and colocalization of synaptophysin and synaptoporin in the hippocampal formation. (A) Synaptophysin immunostaining revealed large mossy fibre boutons in the stratum lucidum (SL) and smaller terminals in all other fields of the hippocampal formation [e.g. in the pyramidal cell (PC) layer and the stratum radiatum (SR)]. (B) Synaptoporin immunoreaction is restricted to the mossy fibre boutons in the stratum lucidum (SL). (C) Double immunofluorescence indicated that most mossy fibre boutons contain synaptoporin in addition to synaptophysin (yellow). Scale bar, $25 \mu \mathrm{m}$.

1991 a), is likely to be modulated in these terminals in a very specific way. Since synaptoporin is already present in the mossy fibre terminals during the first postnatal week and in the adult, it is a necessary component during early synaptogenesis and in the adult circuitry. In this respect hippocampal granule neurons differ from striatal neurons, which synthesize first synaptophysin and later synaptoporin (Ovtscharoff et al., 1993).

The time course of maturation of hippocampal granule neurons is well known (Bayer, 1980). Mossy fibre terminals can be specifically stained with a cytochemical reaction that localizes zinc (Haug, 1967); this technique reveals the first axon sproutings of these neurons at P1 (Zimmer, 1978) and their boutons at P3 (Zimmer, 1978). Our observations indicate that hippocampal synaptoporin specifically increases in the mossy fibre terminals during the first week of postnatal life. SNAP-25 (synaptosomal-associated protein of $25 \mathrm{kDa}$ ), a further component of the fusion machinery and a target of botulinum A toxin (Blasi et al., 1993; Schiavo et al., 1993), is incorporated into the terminals by the third week (Oyler et al., 1991). Functional maturation of granule cells parallels the formation of synaptic contacts since weak synaptic field potentials were found at P5 and their synapses revealed characteristic electrophysiological features at P10 (Bliss et al., 1974). This implies that synaptogenesis of the hippocampal granule neurons, storage of zinc, expression of synaptoporin and the onset of function of the mossy fibres are closely correlated.

Zinc, an important endogenous modulator of glutamate receptors (Westbrook and Mayer, 1987; Hollmann et al., 1993) and localized in synaptic vesicles of mossy fibre boutons (Dyck et al., 1993), disappears after long-term potentiation (Sloviter, 1985). This suggests a close relationship between synaptoporin-positive vesicle membranes and the co-release of zinc (Slomianka, 1992) and glutamate (Assaf and Chung, 1984; Howell et al., 1984) in signalling between dentate granule neurons and pyramidal neurons in the adult.

\section{Acknowledgements}

The authors wish to thank G. Duwe, S. Lewandowski, A. Löchner, E. Roeseler and D. Wachenschwanz for technical assistance. We are also grateful to Prof. H. Traurig, University of Kentucky, Lexington for his helpful comments on the manuscript. This study was supported by Bundesministerium für Forschung und Technologie grant 0316915 A to M. B., by Deutsche Forschungsgemeinschaft (Be 1330 to M. B. and $\mathrm{Gr} 681$ to M. G.) and grants from the Charité (D. G., M. B, P. A. F. and T. S.).

\section{Abbreviations}

$\begin{array}{ll}\text { ABC } & \text { avidin-biotin-peroxidase complex } \\ \text { E } & \begin{array}{l}\text { embryonic day } \\ \text { hippocampal subfield comu ammonis 1 }\end{array} \\ \text { CA1 } & \text { hippocampal subfield comu ammonis 2 } \\ \text { CA2 } & \text { hippocampal subfield cornu ammonis 3 } \\ \text { CA3 } & \text { hippocampal subfield comu ammonis 4 } \\ \text { CA4 } & \text { long-term potentiation } \\ \text { LTP } & \text { postnatal day } \\ \text { P } & \text { phaeochromocytoma cell line PC12 }\end{array}$

\section{References}

Amaral, D. G. (1978) A Golgi study of cell types in the hilar region of the hippocampus in the rat. J. Comp. Neurol., 182, 851-914.

Assaf, S. Y. and Chung, S. H. (1984) Release of endogenous $\mathrm{Zn}^{2+}$ from brain tissue during activity. Nature, 308, 734-736. 
Bayer, S. A. (1980) Development of the hippocampal region in the rat II. Morphogenesis during embryonic and early postnatal life. J. Comp. Neurol., 190, 115-134.

Bergmann, M., Lahr, G., Mayerhofer, A. and Gratzl, M. (1991) Expression of synaptophysin during the prenatal development of the rat spinal cord correlation with basic differentiation processes of neurons. Neuroscience, 42, 569-582.

Bergmann, M., Schuster, T., Grabs, D., Marquèze-Pouey, B., Betz, H., Traurig, H., Mayerhofer, A. and Gratzl, M. (1993) Synaptophysin and synaptoporin expression in the developing rat olfactory system. Dev. Brain Res., 74, 235-244.

Betz, H. (1990) Homology and analogy in transmembrane channel design: lessons from synaptic membrane proteins. Biochemistry, 29, 359l-3599.

Blackstad, T. W, and Kjaerheim, A. (1961) Special axo-dendritic synapses in the hippocampal cortex: electron and light microscopic studies on the layer of mossy fibers. J. Comp. Neurol., 117, 113-159.

Blasi, J., Chapman, E. R., Link, E., Binz, T., Yamasaki, S., De Camilli, P., Südhof, T. C., Niemann, H. and Jahn, R. (1993) Botulinum neurotoxin A selectively cleaves the synaptic protein SNAP-25. Nature, 365, 160-163.

Bliss, T. V. P., Chung, S. H. and Stirling, R. V. (1974) Structural and functional development of the mossy fibre system in the hippocampus of the postnatal rat. J. Physiol. (Lond.), 239, 92-94.

Cameron, P. L., Südhof, T. C., Jahn, R. and De Camilli, P. (1991) Colocalization of synaptophysin with transferrin receptors: Implications for synaptic vesicle biogenesis. J. Cell Biol., 115, 151-164.

Crawford, I. L. and Connor, J. D. (1973) Localization and release of glutamic acid in relation to the hippocampal mossy fibre pathway. Nature, 244, 442-443.

Dyck, R., Beaulieu, C. and Cynader, M. (1993) Histochemical localization of synaptic zinc in the developing cat visual cortex. J. Comp. Neurol., 329, 53-67.

Feany, M. B., Yee, A. G., Delvy, M. L. and Buckley, K. M. (1993) The synaptic vesicle proteins SV2, synaptotagmin and synaptophysin are sorted to separate cellular compartments in CHO fibroblasts. J. Cell Biol., 123, 575-584

Frotscher, M. (1985) Mossy fibres form synapses with identified pyramidal basket cells in the $\mathrm{CA} 3$ region of the guinea-pig hippocampus: a combined Golgi-electron microscope study. J. Neurocytol., 14, 245-259.

Fykse, E. M., Takei, K., Walch-Solimena, C., Geppert, M., Jahn, R., De Camilli, P. and Südhof, T. C. (1993) Relative properties and localizations of synaptic vesicle protein isoforms: the case of the synaptophysins. $J$. Neurosci., 13, 4997-5007.

Haug, F.-M. S. (1967) Electron microscopical localisation of the zinc in hippocampal mossy fiber synapses by a modified sulphide silver procedure. Histochemie, 8, 355-368.

Hollmann, M., Boulter, J., Maron, C., Beasley, L., Sullivan, J., Pecht, G. and Heinemann, S. F. (1993) Zinc potentiates agonist-induced currents at certain splice variants of the NMDA receptor. Neuron, 10, 943-954.

Howell, G. A., Welch, M. G. and Frederickson, C. J. (1984) Stimulationinduced uptake and release of zinc in hippocampal slices. Nature, 308, 736-738.

Hsu, S.-M., Raine, L. and Fanger, H. (1981) Use of avidin-biotin-peroxidase complex $(A B C)$ in immunoperoxidase techniques: a comparison between $\mathrm{ABC}$ and unlabeled antibody (PAP) procedures. J. Histochem. Cytochem., 29, 577-580

Jahn, R. and De Camilli, P. (1991) Membrane proteins of synaptic vesicles: Markers for neurons and neuroendocrine cells; tool for the study of neurosecretion. In Gratzl, M. and Langley, K. (eds), Markers for Neural and Endocrine Cells, Vol 1. VCH-Verlagsgesellschaft, Weinheim, pp. 25-92.

Jahn, R. and Südhof, T. C. (1994) Synaptic vesicles and exocytosis. Annu. Rev. Neurosci., 17, 219-246.

Johnston, P. A., Cameron, P. L., Stukenbrok, H., Jahn, R., De Camilli, P. and Südhof, T. C. (1989a) Synaptophysin is targeted to similar microvesicles in CHO- and PC12-cells. EMBO J., 8, 2863-2872.

Johnston, P. A., Jahn, R. and Südhof, T. C. (1989b) Transmembrane topography and evolutionary conservation of synaptophysin. J. Biol. Chem., 264, 1268-1273.

Knaus, P., Marquèze-Pouey, B., Scherer, H. and Betz, H. (1990) Synaptoporin, a novel putative channel protein of synaptic vesicles. Neuron, 5, 453-462.
Laemmli, U. K. (1970) Cleavage of structural proteins during the assembly of the head of bacteriophage T4. Nature, 227, 680-685.

Lah, J. J. and Burry, R. W. (1993) Synaptophysin has a selective distribution in early endosomes of PC12 cells. J. Neurocytol., 22, 92-101.

Lahr, G., Heiss, C., Mayerhofer, A., Schilling, K., Parmer, R. J., O'Connor, D. T. and Gratzl, M. (1990) Chromogranin A in the olfactory system of the rat. Neuroscience, 39, 605-611.

Linstedt, A. D. and Kelly, R. B. (1991a) Endocytosis of the synaptic vesicle

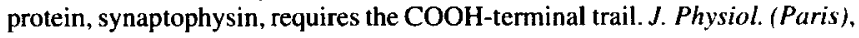
85, 90-96.

Linstedt, A. D. and Kelly, R. B. (1991b) Synaptophysin is sorted from endocytic markers in neuroendocrine PC12 cells but not transfected fibroblasts. Neuron, 7, 309-317.

Marquèze-Pouey, B., Wisden, W., Malosio, M. L. and Betz, H. (1991) Differential expression of synaptophysin and synaptoporin mRNAs in the postnatal rat central nervous system. J. Neurosci., 11, 3388-3397.

Mundigl, O., Matteoli, M., Daniell, L., Thomas-Reetz, A., Metcalf, A., Jahn, R. and De Camilli, P. (1993) Synaptic vesicle proteins and early endosomes in cultured hippocampal neurons: differential effects of Brefeldin $A$ in axon and dendrites. J. Cell Biol., 122, 1207-1221.

O'Connor, V. M., Shamotienko, O., Grishin, E. and Betz, H. (1993) On the structure of the 'synaptosecretosome': evidence for a neurexin/ synaptotagmin/syntaxin/Ca ${ }^{2+}$ channel complex. FEBS Lett., 326, 255-260.

Ovtscharoff, W., Bergmann, M., Marquèze-Pouey, B., Knaus, P., Betz, H., Grabs, D., Reisert, I. and Gratzl, M. (1993) Ontogeny of synaptophysin and synaptoporin in the central nervous system: differential expression in striatal neurons and their afferents during development. Dev. Brain Res., 72, 219-225.

Oyler, G. A., Polli, J. W., Wilson, M. C. and Billingsley, M. L. (1991) Developmental expression of the $25-\mathrm{kDa}$ synaptosomal-associated protein (SNAP-25) in rat brain. Proc. Natl Acad. Sci. USA, 88, 5247-5251.

Régnier-Vigouroux, A., Tooze, S. A. and Huttner, W. B. (1991) Newly synthesized synaptophysin is transported to synaptic-like microvesicles via constitutive secretory vesicles and the plasma membrane. EMBO J., 10, 3589-3601.

Scarfone, E., Dememes, D. and Sans, A. (1991) Synapsin I and synaptophysin expression during ontogenesis of the mouse peripheral vestibular system. J. Neurosci., 11, 1173-1181.

Schiavo, G., Santucci, A., DasGupta, B. R., Mehta, P. P., Jontes, J., Benfenati, F., Wilson, M. C. and Montecucco, C. (1993) Botulinum neurotoxins serotypes $A$ and $E$ cleave SNAP-25 at distinct $\mathrm{COOH}$-terminal peptide bonds. FEBS Lett., 335, 99-103.

Schilling, K. and Gratzl, M. (1988) Quantification of p38/synaptophysin in highly purified adrenal medullary chromaffin vesicles. FEBS Lett., 233 , 22-24

Schmied, R. and Holtzman, E. (1989) Involvement of the Golgi apparatus in sorting of materials to opposite ends of frog rod retinal photoreceptors. $J$. Neurobiol., 20, 115-138.

Slomianka, L. (1992) Neurons of origin of zinc-containing pathways and the distribution of zinc-containing boutons in the hippocampal region of the rat. Neuroscience, $48,325-352$.

Sloviter, R. S. (1985) A selective loss of hippocampal mossy fiber TIMM stain accompanies granule cell seizure activity induced by perforant path stimulation. Brain Res., 330, 150-153.

Söllner, T., Bennett, M. K., Whiteheart, S. W., Scheller, R. H. and Rothman, J. E. (1993) A protein assembly-disassembly pathway in vitro that may correspond to sequential steps of synaptic vesicle docking, activation, and fusion. Cell, 75, 409-418.

Thomas, L., Hartung, K., Langosch, D., Rehm, H., Bamberg, E., Franke, W. W. and Betz, H. (1988) Identification of synaptophysin as a hexameric channel protein of the synaptic vesicle membrane. Science, 242, 1050-1053.

Towbin, H., Staehelin, T. and Gordon, J. (1979) Electrophoretic transfer of proteins from polyacrylamide gels to nitrocellulose sheets: procedure and some applications. Proc. Natl Acad. Sci. USA, 76, 4350-4353.

Westbrook, G. L. and Mayer, M. L. (1987) Micromolecular concentrations of $\mathrm{Zn}^{2+}$ antagonize NMDA and GABA responses of hippocampal neurons. Nature, 328, 640-643.

Zimmer, J. (1978) Development of the hippocampus and fascia dentata: morphological and histochemical aspects. Prog. Brain Res., 48, 171-190. 